\title{
Farnesylation of Zebrafish G Protein-Coupled Receptor Kinase Using Bio-Orthogonal Labeling
}

Nicole Ahrens, ${ }^{\ddagger}$ Enno Aeissen,, Anka Lippe," Ulrike Janssen-Bienhold," Jens Christoffers," and Karl-Wilhelm Koch, ${ }^{*,}$

${ }^{\ddagger}$ Division of Biochemistry, Department of Neurosciences, Carl von Ossietzky Universität Oldenburg, D-26111 Oldenburg, Germany.

\#Institut für Chemie, Carl von Ossietzky Universität Oldenburg, D-26111 Oldenburg, Germany. \|Division of Neurobiology, Department of Neurosciences, Carl von Ossietzky Universität Oldenburg, D-26111 Oldenburg, Germany.

\section{Supporting Information}

1. Multiple sequence alignment of C-terminal regions in zebrafish GRKs

Consensus sequence $C_{a_{1}} a_{2} \mathbf{X}\left(C=\right.$ cysteine, $a_{1} a_{2}=$ two aliphatic amino acids, but position $a_{1}$ is flexible; $\left.X=C, S, Q, A, M, T, H, V, N, F, G, I\right)$ 
2. NMR-Spectra of all Reported Compounds

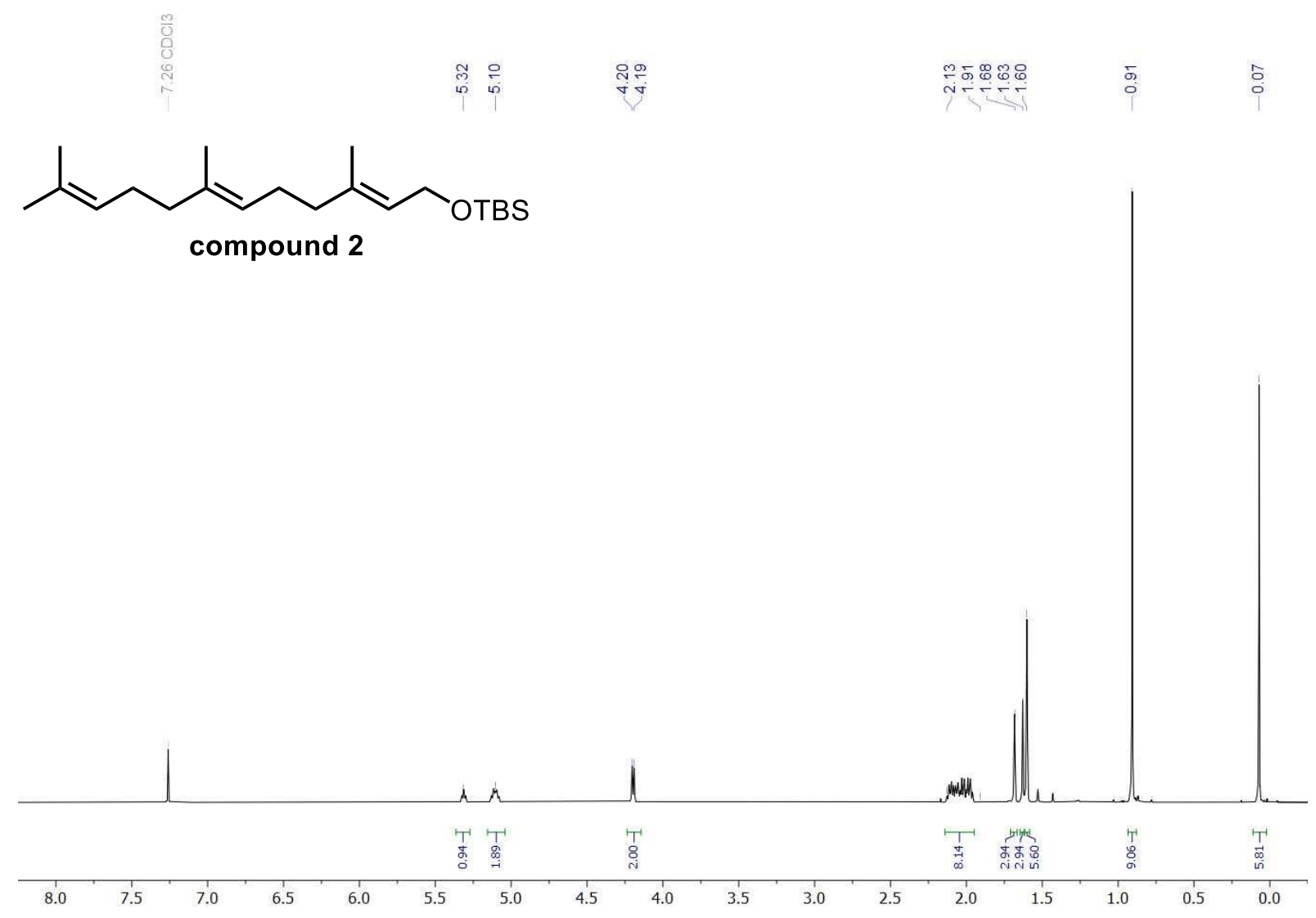

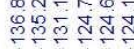

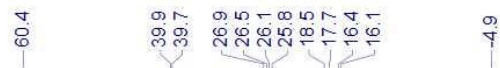

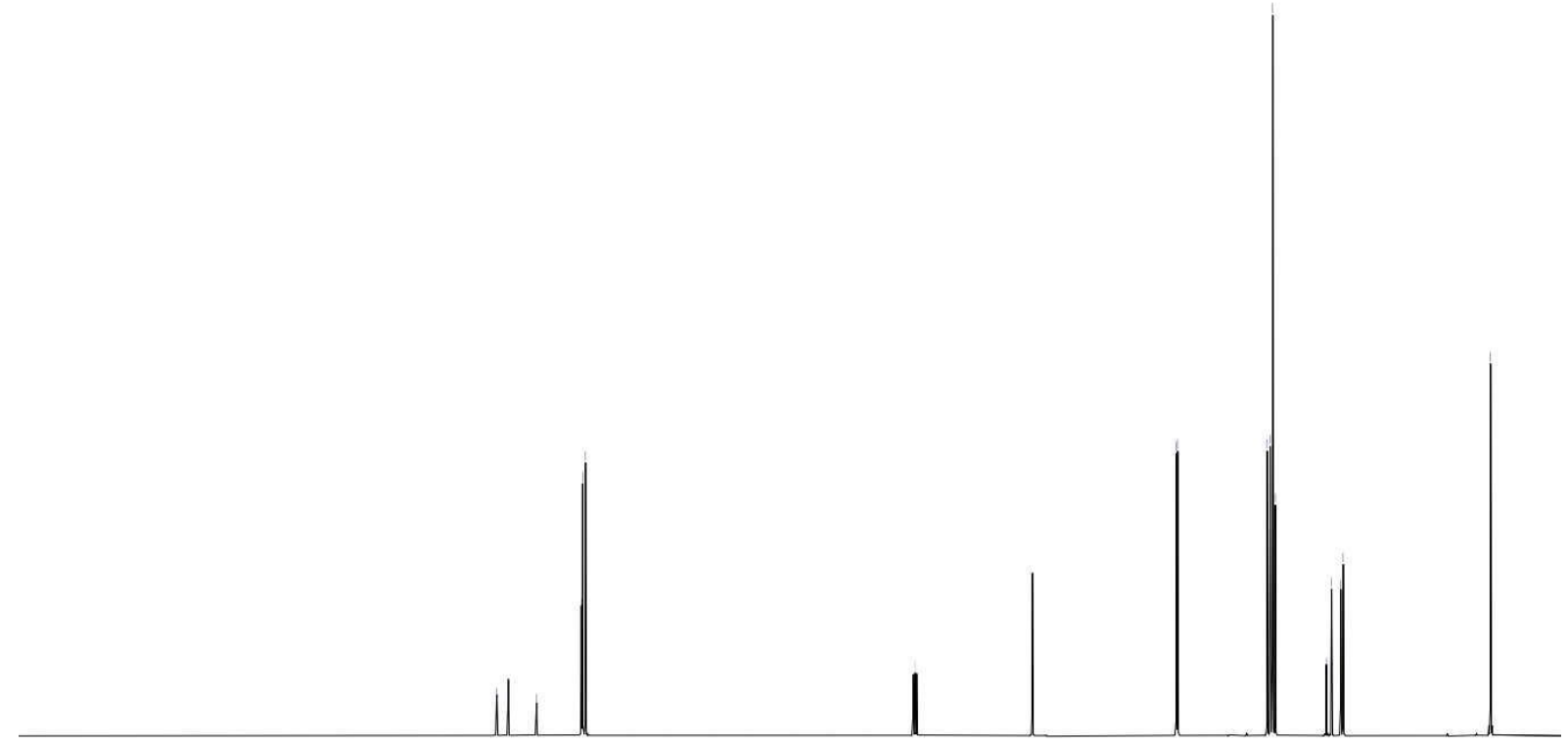

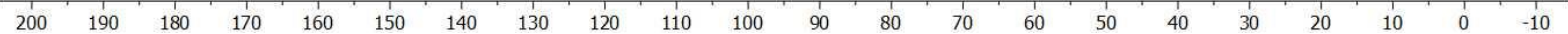



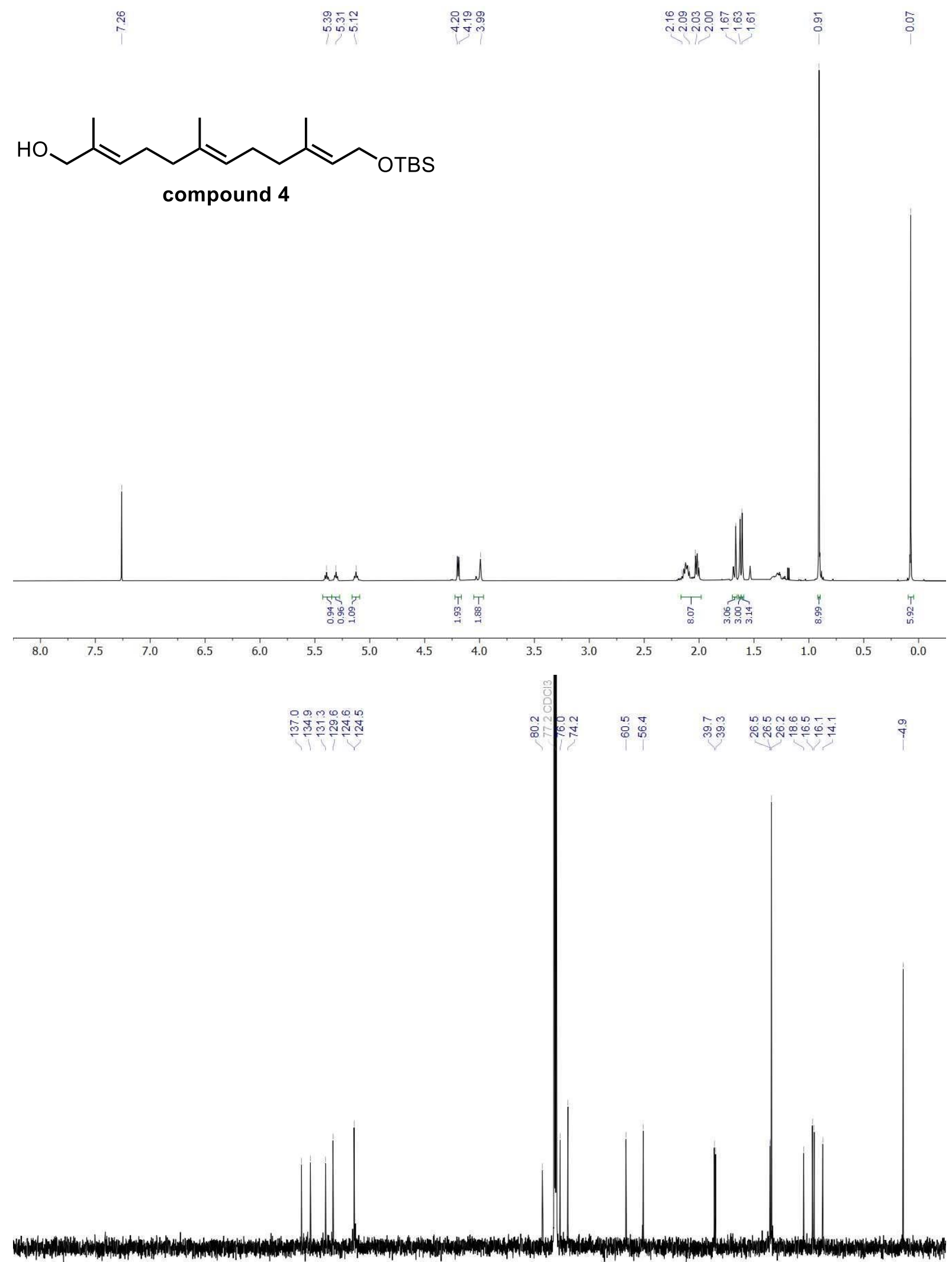

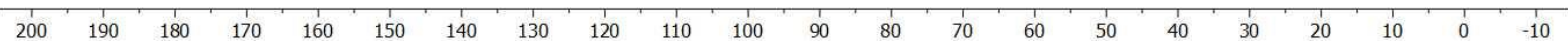




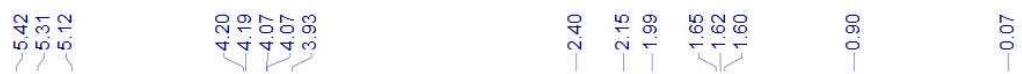
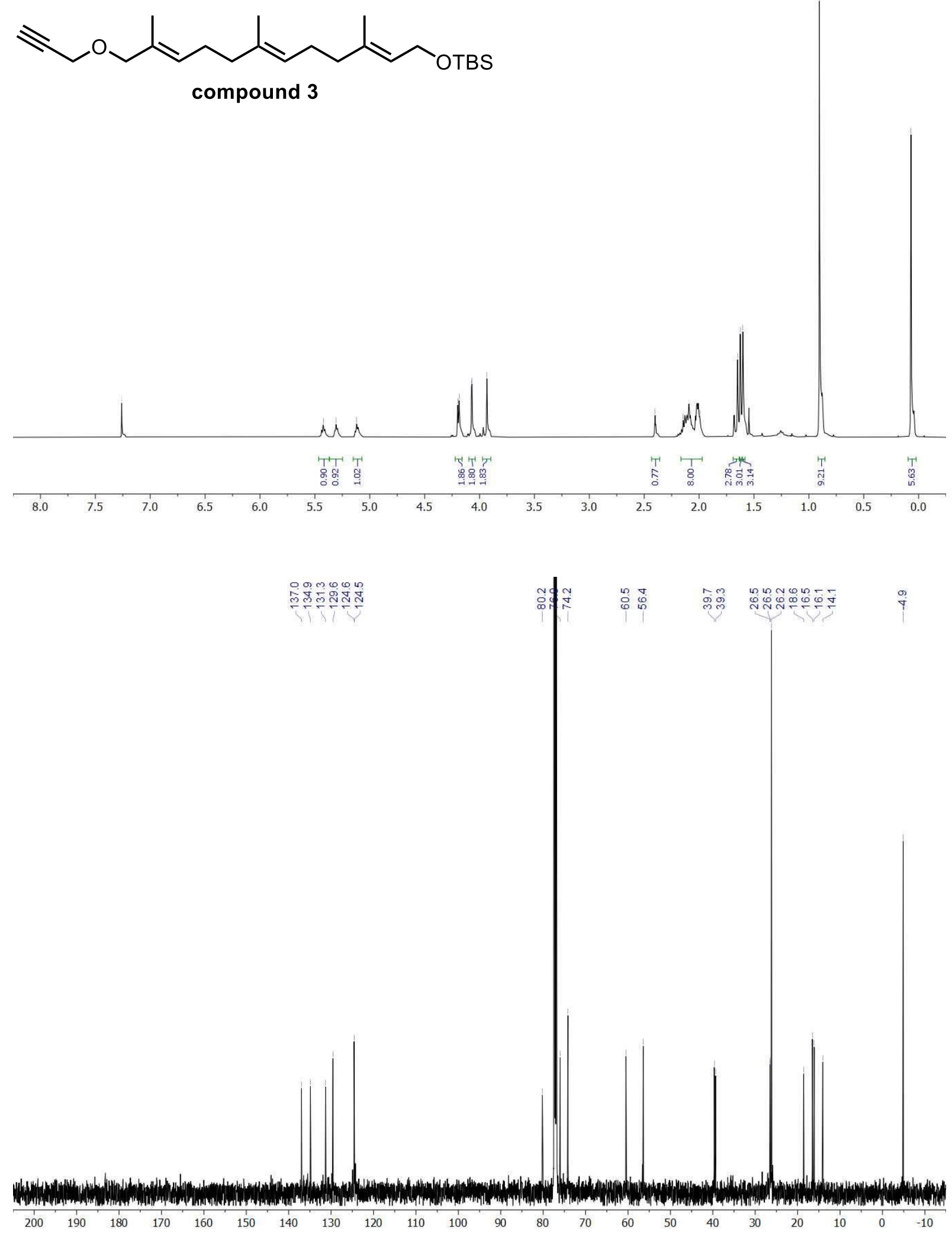

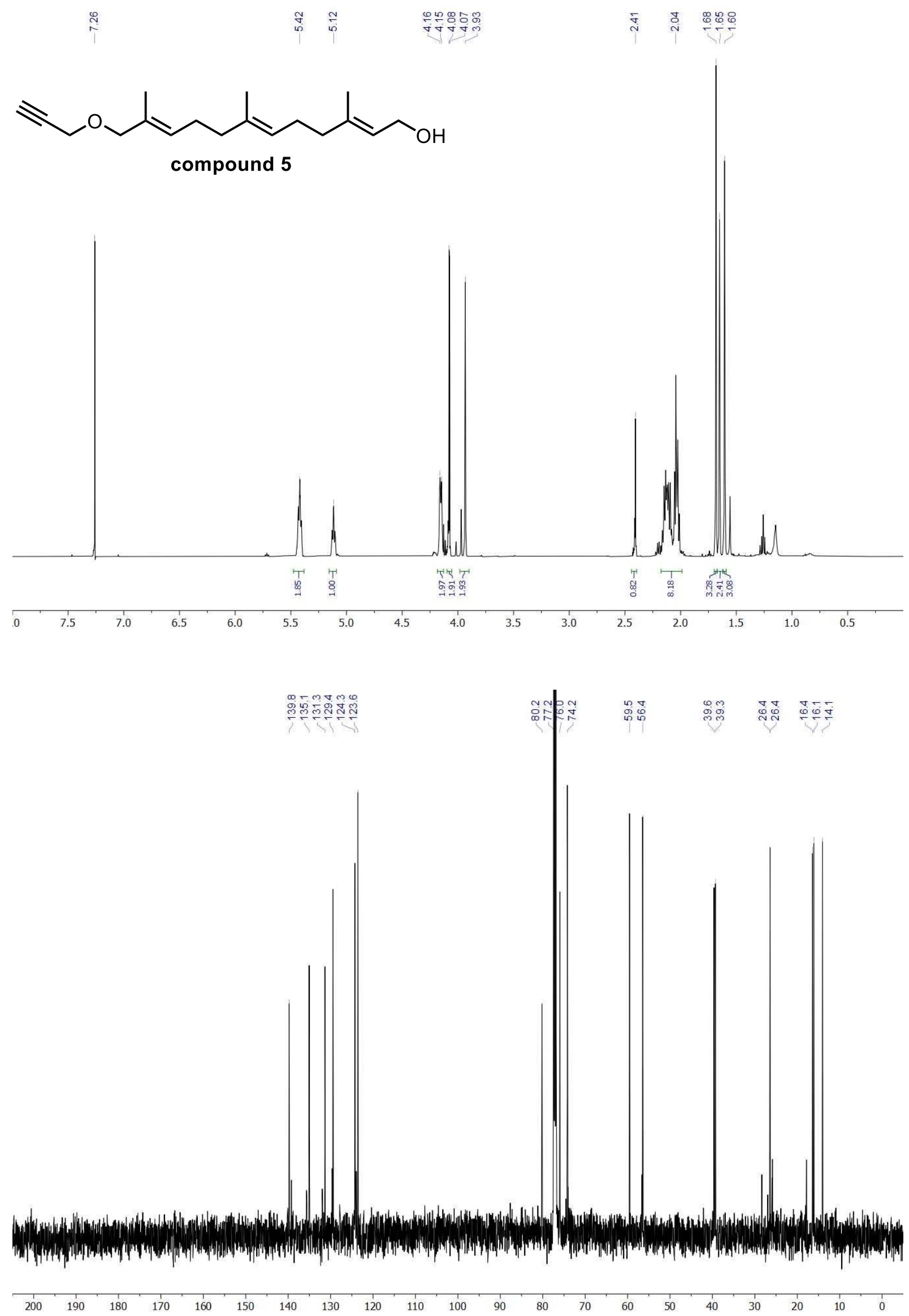

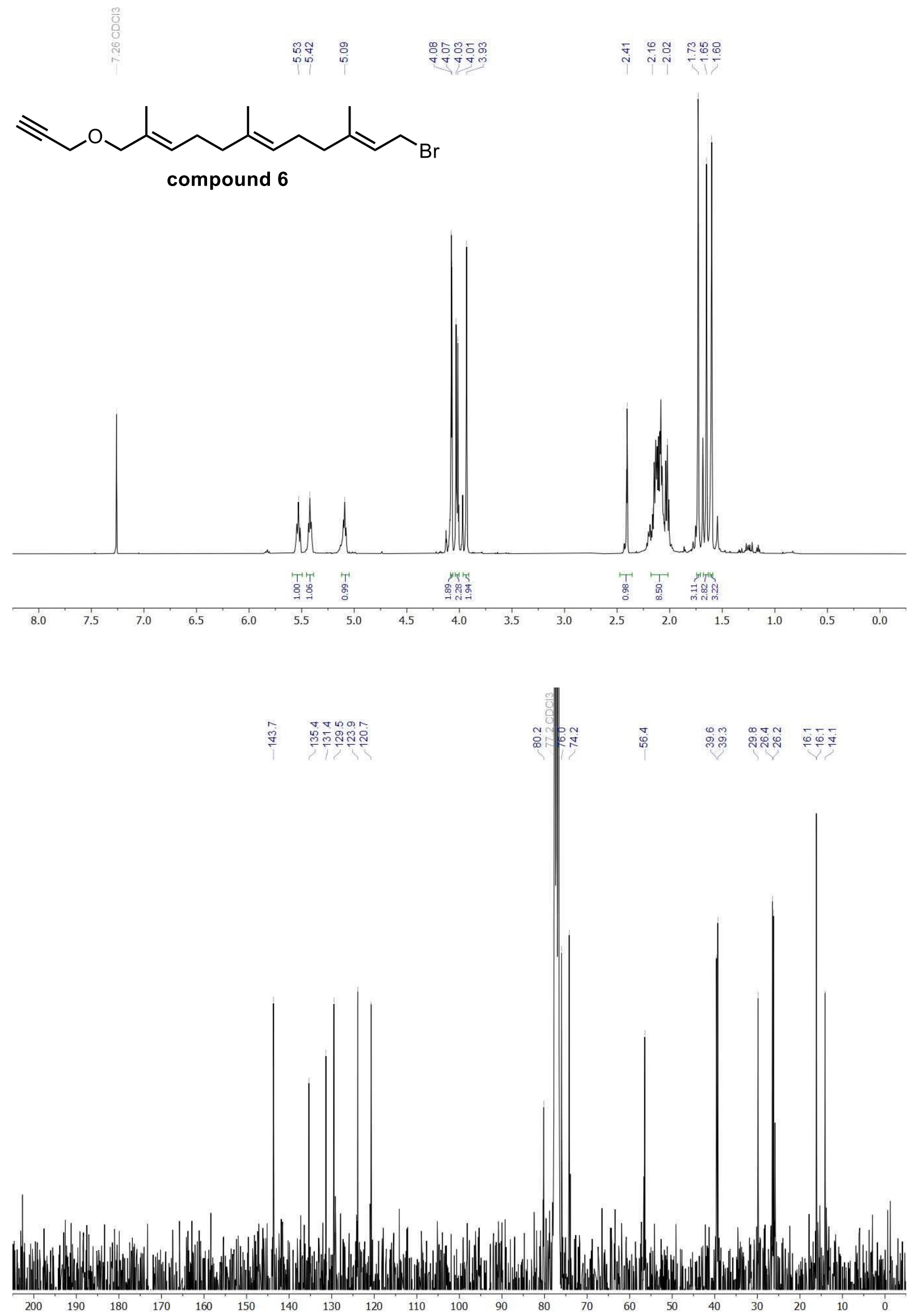


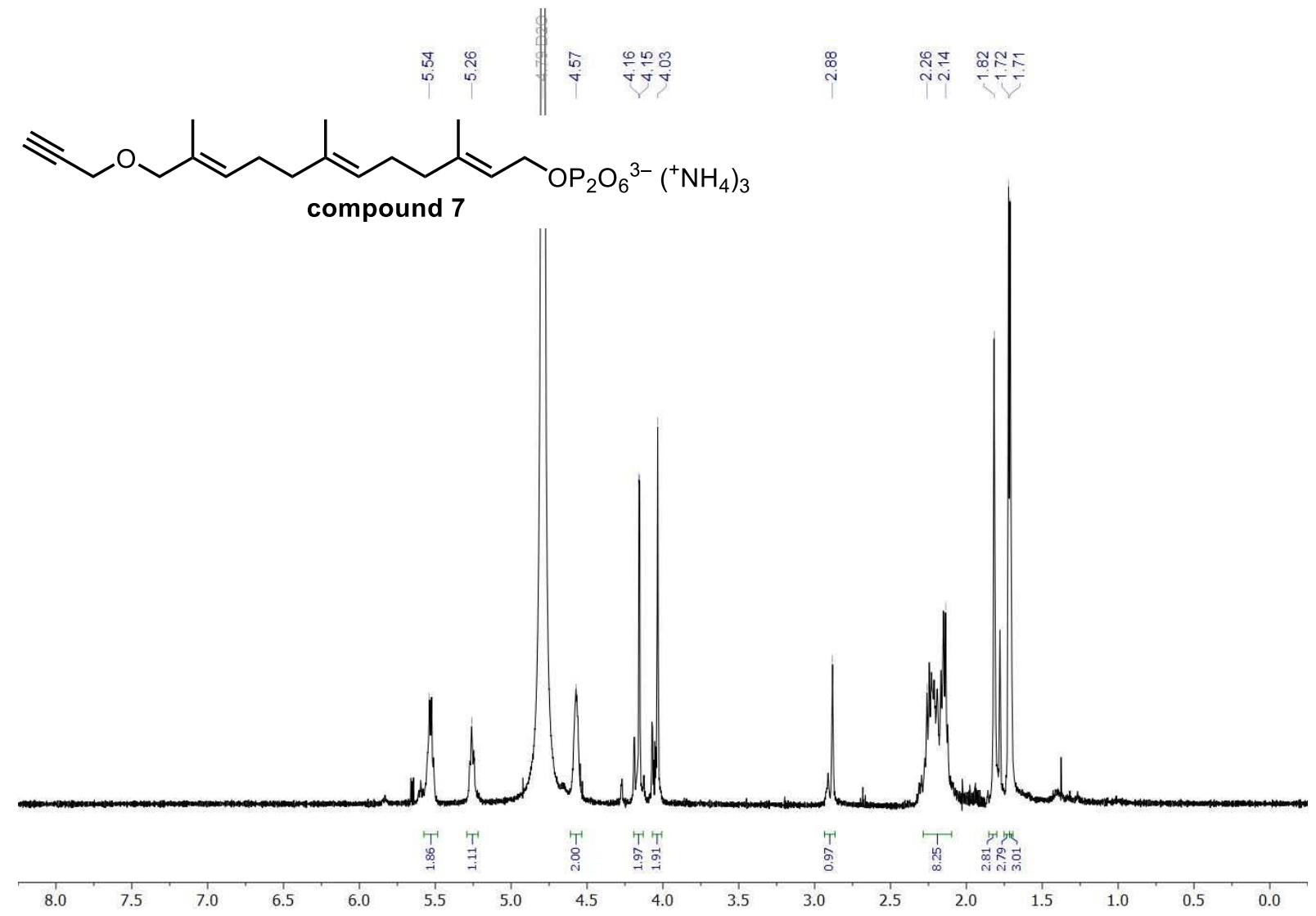

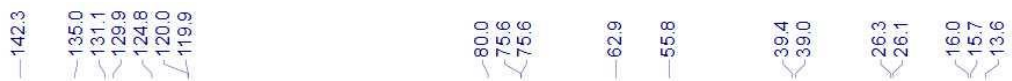

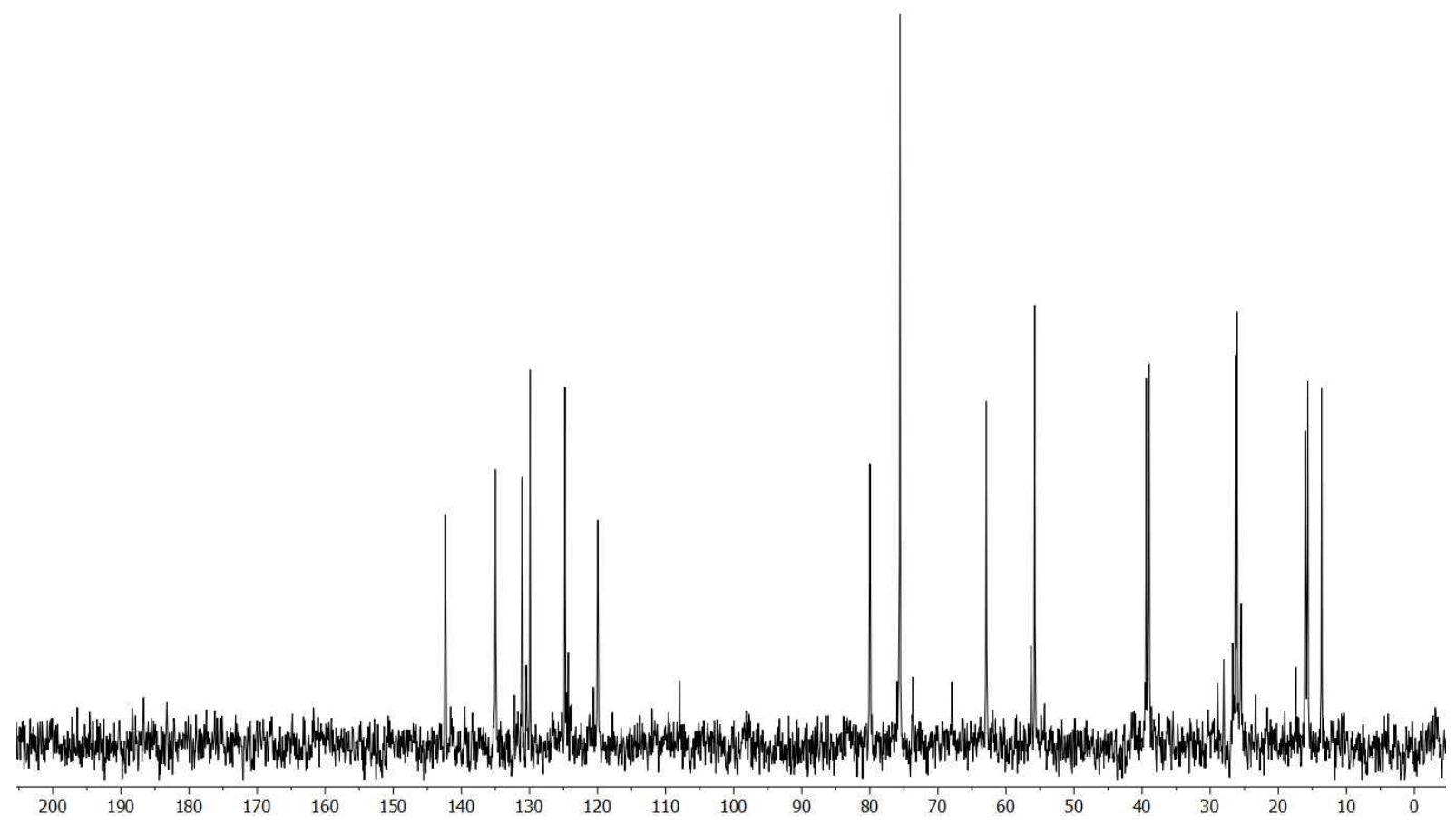



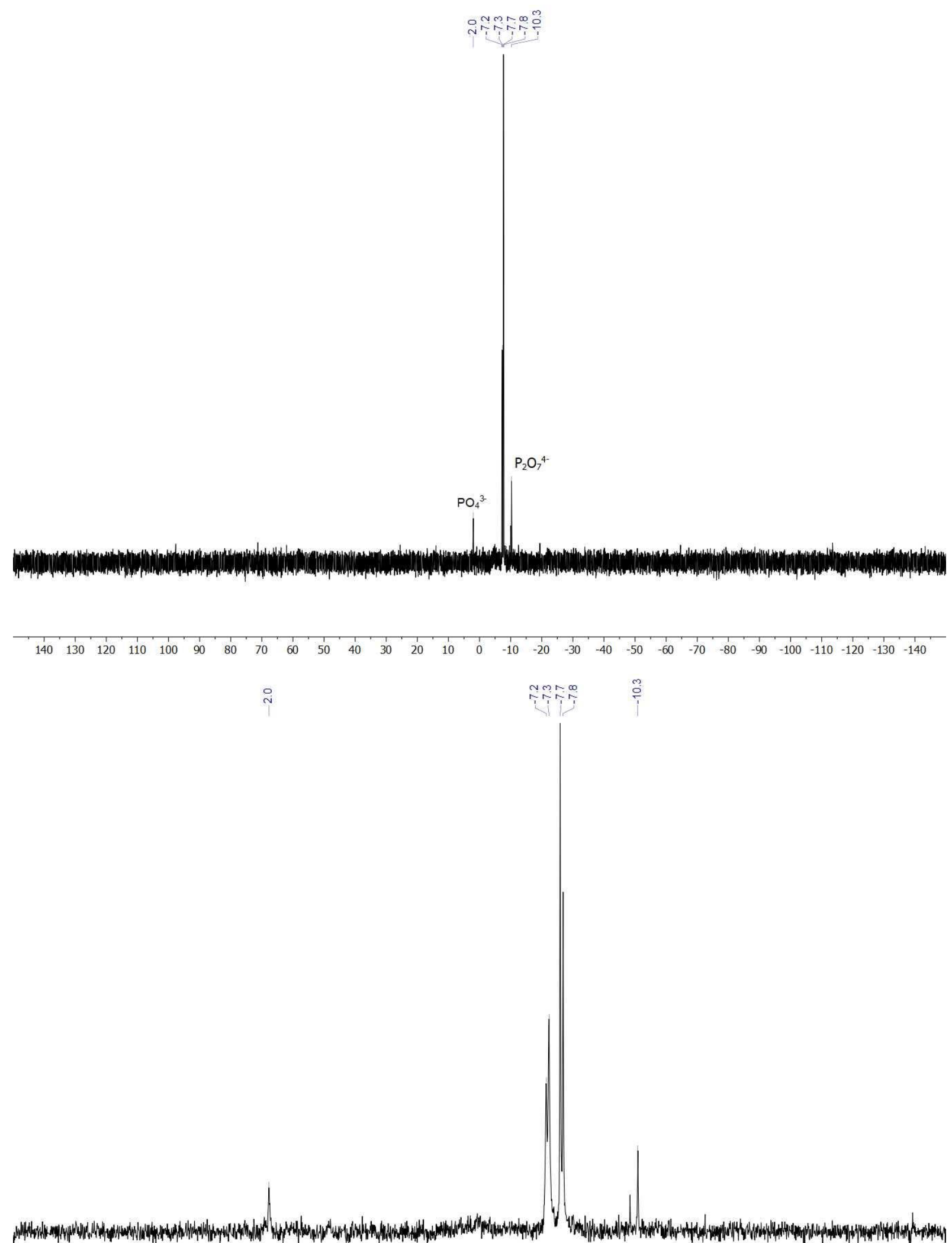

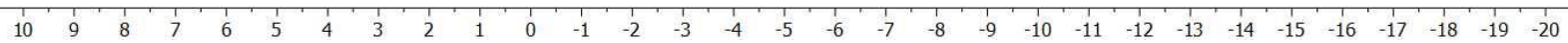

